\title{
Pulmonary Function Testing and Outcomes in Subjects With Heart Failure Listed for Heart Transplantation
}

\author{
Vasiliki V Georgiopoulou MD MPH, Anjan Deka MD, Song Li MD, Anum A Niazi MD, \\ Kanwal Farooq MBBS, Andreas P Kalogeropoulos MD MPH PhD, Javed Butler MD MPH, and \\ Dimitrios Alexopoulos MD PhD
}

\begin{abstract}
BACKGROUND: Impaired spirometric parameters have been reported in patients with stage C heart failure and portend worse outcomes in these patients. The impact of spirometric parameters on outcomes in patients with stage $D$ heart failure listed for heart transplantation is unknown. METHODS: We collected data on consecutive subjects listed for heart transplantation and examined the association of $\mathrm{FEV}_{1}, \mathrm{FVC}$, and $\mathrm{FEV}_{1} / \mathrm{FVC}$ with (1) death or left ventricular assist device implantation (primary end point) and (2) death, left ventricular assist device implantation, or urgent transplantation (secondary end point). In a secondary analysis, we examined the association of baseline spirometry with post-transplant outcomes. RESULTS: Among 187 subjects $(53 \pm 10 \mathrm{y}$ old, $17.1 \%$ women, $69.5 \%$ white subjects, $28.9 \%$ black subjects), there were 19 deaths, 28 left ventricular assist device implantations, and 74 urgent transplantations (primary end point of $25.1 \%$, secondary end point of $64.7 \%$ ) after a median of 5.5 months (interquartile range of 2.3-15.2). For $\mathrm{FEV}_{1}$, the hazard ratios for the primary and secondary end points were 0.93 (95\% CI 0.61-1.41, $P=.72)$ and $0.94(95 \% \mathrm{CI} 0.72-1.21, P=.62)$ per $\mathrm{L}$, respectively. The hazard ratios of FVC were $0.90(95 \%$ CI $0.65-1.25, P=.52)$ and $0.92(95 \%$ CI $0.76-1.13, P=.43)$ per $\mathrm{L}$, respectively. Impairment patterns (obstructive, restrictive, mixed) were not associated with risk for events. There was no interaction of spirometric parameters with smoking or lung disease for outcomes. Baseline spirometry was not associated with perioperative 30-d mortality (1.4\%) and 1-y posttransplant survival (97.1\%). CONCLUSIONS: In contrast to stage $C$ subjects with heart failure, spirometric parameters were not associated with outcomes in this homogeneous stage $D$ heart failure population. Key words: heart failure; heart transplantation; spirometry; prognosis. [Respir Care 2015;60(5):731-739. @ 2015 Daedalus Enterprises]
\end{abstract}

\section{Introduction}

Heart failure is a chronic debilitating condition with increasing prevalence and significant morbidity and mortality. ${ }^{1-4}$ Improved outcomes of acute cardiac conditions, population aging, increasing prevalence of lifestyle-related

\footnotetext{
Drs Georgiopoulou, Deka, Li, Farooq, Kalogeropoulos, Butler, and Niazi are affiliated with the Emory Clinical Cardiovascular Research Institute, Emory University, Atlanta, Georgia. Drs Georgiopoulou and Alexopoulos are affiliated with the Department of Cardiology, University of Patras, Patras, Greece.
}

This study was partially funded through an Emory University Heart and Vascular Board grant entitled "Novel Risk Markers and Prognosis Determination in Heart Failure." The authors have disclosed no conflicts of interest. risk factors, and advances in heart failure therapy have all led to an ever-increasing prevalence of heart failure. Because of these trends, heart failure is currently considered an epidemic and a public health priority in developed countries. ${ }^{5-7}$ Approximately 5-10\% of the heart failure population is estimated to have advanced (stage D) heart failure. ${ }^{8}$ Mortality in this group remains high, with projected 2-y survival of $<40 \% .{ }^{9}$ Despite advances in both medical and destination left ventricular assist device therapy, heart

\footnotetext{
Correspondence: Vasiliki V Georgiopoulou MD MPH, Emory Clinical Cardiovascular Research Institute, Suite 535A, 1462 Clifton Road, NE, Atlanta, GA 30322. E-mail: vgeorgi@emory.edu.
}

DOI: $10.4187 /$ respcare.03709 
transplantation remains the optimal intervention for longterm survival and quality of life for patients with stage D heart failure. A 1-y post-transplant survival of $90 \%$, with a $50 \%$ survival rate noted at $11 \mathrm{y}$, has been reported. ${ }^{10}$

Despite improvements in transplant outcomes, donor heart availability continues to be the main barrier, with annual transplant numbers remaining stagnant at $\sim 2,000$ transplants/y from 2000 to 2011 in the United States. ${ }^{11}$ With high demand and limited availability, the transplant evaluation process remains tenuous. Patients are evaluated in terms of physical, psychological, and social attributes, with some inter-institutional variation in the process. Among the absolute contraindications for heart transplantation is significant obstructive pulmonary disease, ${ }^{8}$ underscoring the importance of pulmonary function for transplant outcomes. Thus, spirometry is an inherent part of the evaluation process. ${ }^{8}$ Both obstructive and restrictive patterns have been seen in subjects with heart failure and no history of tobacco use or prior lung or pleural space disease. ${ }^{12-15}$ Studies have shown a correlation between severity of pulmonary function abnormalities and severity of heart failure. ${ }^{12,16}$ Of note, subjects with advanced heart failure were reported to have more severe abnormalities than those with milder presentations..$^{12,17}$

Impaired pulmonary function has also been proposed as a cardiovascular risk factor ${ }^{18}$ and has been associated with all-cause and cardiovascular mortality. ${ }^{19,20}$ Specifically to heart failure, spirometric parameters have been demonstrated to predict incident heart failure ${ }^{21-23}$ and outcomes of patients with stage $\mathrm{C}$ heart failure. ${ }^{17,24-26}$ However, the association of spirometric parameters with outcomes in patients with advanced (stage D) heart failure listed for heart transplantation is less clear. Patients referred for heart transplantation represent a more homogeneous population in which left ventricular function is severely impaired and congestive symptoms are common.

In this study, we investigated the association of resting spirometric parameters with outcomes (mortality, need for left ventricular assist device implantation, or urgent heart transplantation) in a cohort of subjects listed for heart transplantation. In a secondary analysis, we also examined the association of baseline spirometry with post-transplant survival.

\section{Methods}

\section{Subject Population}

We collected data on consecutive adults ( $\geq 18$ y) listed for heart transplantation between January 2000 and December 2012 at Emory University. Patients with heart failure secondary to congenital heart disease were excluded. A total of 345 subjects fulfilling these criteria were listed for heart transplantation: 43 (12.5\%) were listed as United

\section{QUICK LOOK}

\section{Current knowledge}

Heart failure is a chronic debilitating condition with an increasing prevalence and significant morbidity and mortality. Approximately 5-10\% of patients with heart failure have advanced (stage D) disease. Mortality remains high, with a projected 2-y survival of $<40 \%$. Heart transplantation remains the optimal intervention for long-term survival and quality of life, with a 1-y post-transplant survival of $90 \%$.

\section{What this paper contributes to our knowledge}

Spirometric parameters were not associated with outcomes in the homogeneous group of subjects with heart failure listed for heart transplantation. Severe heart failure led to significant reductions in $\mathrm{FEV}_{1}$ and FVC, suggesting that the majority of patients with advanced heart failure will have impaired spirometric values.

Network for Organ Sharing (UNOS) status 1A, 153 (44.3\%) as status $1 \mathrm{~B}$, and $149(43.2 \%)$ as status 2. Among these subjects, $187(54.2 \%)$ had spirometric data available and constituted our main study population for this analysis. The institutional review board approved the study.

\section{Data Collection}

Demographics, clinical information, and laboratory and hemodynamic data were abstracted from paper and electronic medical records. We considered the date of initial listing status as the baseline date for the study. Medical history, physical examination, and laboratory data were abstracted from the clinic visits closest to the date of listing. Subjects were regularly followed in the Center for Heart Failure and Transplantation at Emory University. Information on outcomes was collected through medical records from planned and unplanned clinic visits, admissions, surgical procedures, in-hospital progress notes, and discharge summaries. The vital status of subjects censored as alive as of December 2012 was confirmed through the scheduling and communication modules of the Emory electronic health records system. Out-of-hospital deaths are captured in the Emory Clinical Data Warehouse through linkage to the Social Security Death Index. No subject was lost to clinical follow-up.

\section{Definition of Variables}

History of smoking and alcohol abuse was considered as present based on information given by the subjects. 


\section{Spirometry in SubJects Listed for Heart Transplantation}

History of myocardial infarction, coronary artery bypass grafting, and percutaneous coronary intervention was considered as positive when there was information about a previous event, surgery, and intervention written in subjects' notes in the medical history. We defined prevalent coronary artery disease as history of myocardial infarction, coronary artery bypass grafting, or percutaneous coronary intervention. History of hypertension, diabetes, dyslipidemia, chronic lung disease, sleep apnea, CPAP use, depression, atrial and ventricular arrhythmias, and cardiac device implantation (biventricular pacemaker, automatic implantable cardiac defibrillator, or both) was based on documentation of these conditions in subjects' medical records by the time of listing for heart transplantation. We defined lung disease as the presence of COPD, asthma, or sarcoidosis. Atrial arrhythmias included permanent and paroxysmal atrial fibrillation or flutter. Information on medical history was considered valid when it was reported in more than one note in the medical record. Because of the possibility of interaction between smoking, lung disease history, and diabetes mellitus, a condition that has been reported to affect pulmonary function, ${ }^{27}$ we tested for possible interaction between spirometric variables and smoking, lung disease, and diabetes.

\section{Spirometry}

Spirometry was performed with a horizontal dry rollingseal spirometer (SensorMedics, Yorba Linda, California) with subjects in a sitting position using the acceptability and reproducibility criteria and the selection of maneuvers proposed in the recommendations of the American Thoracic Society. ${ }^{28}$ In this analysis, we considered absolute and percent-of-predicted $\mathrm{FEV}_{1}$ and $\mathrm{FVC}$ and the $\mathrm{FEV}_{1} / \mathrm{FVC}$ ratio. Spirometric obstructive ventilatory pattern was defined as a combination of $\mathrm{FEV}_{1} / \mathrm{FVC}<0.70$ and $\mathrm{FEV}_{1}<80 \%$ of predicted; restrictive ventilatory pattern was defined as a combination of $\mathrm{FEV}_{1} / \mathrm{FVC} \geq 0.70$ and $\mathrm{FVC}<80 \%$ of predicted; and mixed pattern was defined as a combination of $\mathrm{FEV}_{1} / \mathrm{FVC}<0.70, \mathrm{FEV}_{1}<80 \%$ of predicted, and FVC $<80 \%$ of predicted. ${ }^{29}$

\section{Outcomes}

We collected data on vital status, left ventricular assist device implantation, heart transplantation, and UNOS status at the time of transplantation. The primary end point of interest was the time to death or left ventricular assist device implantation (whichever occurred first). The secondary end point was defined as death or urgent transplantation (UNOS status 1A) or left ventricular assist device implantation. Post-transplant vital status was assessed from the heart transplant clinic records.

\section{Statistical Analysis}

Descriptive statistics are presented as mean \pm SD for continuous variables and as number and percentage for categorical variables. To assess bivariate associations between clinical characteristics and spirometric parameters, we used unpaired $t$ tests for binary characteristics and Pearson correlation for continuous characteristics. The association of spirometric parameters with the primary and secondary end points was examined with Cox proportional hazards models. We examined the appropriate functional form for the association of spirometric parameters with outcomes (linear vs nonlinear forms) using fractional polynomials and restricted cubic splines as described by Royston and co-workers. ${ }^{30}$ The validity of the proportional hazards assumption was tested with Schoenfeld residuals. For the primary end point, subjects who did not die or receive a left ventricular assist device were censored as alive at the time of heart transplantation or end of follow-up. For the secondary end point, subjects who did not die, receive a left ventricular assist device, or receive urgent heart transplantation were censored as alive at the time of non-urgent heart transplantation or end of follow-up. To examine for significant modification effects (interactions), we introduced appropriate interaction terms in the models. We also examined the association of the various ventilatory patterns with outcomes using a normal ventilatory pattern as the reference category. Finally, we searched for differences in outcomes between subjects with and without spirometric data available. The effect of baseline spirometry on post-transplant survival was examined with appropriate Cox models. A 2 -sided $P \leq .05$ was considered statistically significant. All analyses were performed with Stata 13 (StataCorp, College Station, Texas).

\section{Results}

\section{Subject Characteristics and Spirometric Parameters}

The mean age of subjects with spirometric variables $(n=187)$ was $53.1 \pm 10.3 \mathrm{y} ; 32(17.1 \%)$ were women; $130(69.5 \%)$ were white, and $54(28.9 \%)$ were black; and ejection fraction at time of listing was $14.9 \pm 7.5 \%$. The complete baseline subject characteristics are presented in Table 1, and the baseline central hemodynamics of subjects are presented in Table 2. Absolute and percent-ofpredicted $\mathrm{FEV}_{1}$ were $2.4 \pm 0.7 \mathrm{~L}$ and $67.3 \pm 16.2$, respectively. Absolute and percent-of-predicted FVC were $3.2 \pm 0.9 \mathrm{~L}$ and $72.0 \pm 16.3$, respectively. Mean $\mathrm{FEV}_{1} /$ FVC was $0.74 \pm 0.11$. White subjects had higher $\mathrm{FEV}_{1}$ and FVC compared with non-white subjects $\left(\mathrm{FEV}_{1}\right.$ of $2.5 \pm 0.7 \mathrm{~L}$ in white subjects vs $2.1 \pm 0.5 \mathrm{~L}$ in non-white 


\section{Spirometry in Subjects Listed for Heart Transplantation}

Table 1. Baseline Subject Characteristics

\begin{tabular}{|c|c|}
\hline Characteristic & Values \\
\hline \multicolumn{2}{|l|}{ Demographics and medical history } \\
\hline Age (mean $\pm \mathrm{SD}), \mathrm{y}$ & $53.1 \pm 10.3$ \\
\hline Female, $n(\%)$ & $32(17.1)$ \\
\hline \multicolumn{2}{|l|}{ Race } \\
\hline White, $n(\%)$ & $130(69.5)$ \\
\hline Black, $n(\%)$ & $54(28.9)$ \\
\hline $\mathrm{BMI}($ mean $\pm \mathrm{SD}), \mathrm{kg} / \mathrm{m}^{2}$ & $27.5 \pm 4.6$ \\
\hline Ejection fraction (mean $\pm \mathrm{SD}), \%$ & $14.9 \pm 7.5$ \\
\hline \multicolumn{2}{|l|}{ NYHA class, $n(\%)$} \\
\hline II & $12(6.4)$ \\
\hline III & $113(60.4)$ \\
\hline IV & $62(33.2)$ \\
\hline Coronary artery disease, $n(\%)$ & $80(42.8)$ \\
\hline Myocardial infarction, $n(\%)$ & $76(40.6)$ \\
\hline Coronary artery bypass graft, $n(\%)$ & $47(25.1)$ \\
\hline PTCA, $n(\%)$ & $32(17.1)$ \\
\hline Smoking, $n(\%)$ & $105(56.1)$ \\
\hline Alcohol use, $n(\%)$ & $45(24.1)$ \\
\hline Hypertension, $n(\%)$ & $98(52.4)$ \\
\hline Diabetes, $n(\%)$ & $53(28.3)$ \\
\hline Dyslipidemia, $n(\%)$ & $108(57.7)$ \\
\hline Lung disease, $n(\%)$ & 39 (20.9) \\
\hline Sleep apnea, $n(\%)$ & $32(17.1)$ \\
\hline CPAP use, $n(\%)$ & $28(15.0)$ \\
\hline Depression, $n(\%)$ & $35(18.7)$ \\
\hline \multicolumn{2}{|l|}{ Atrial arrhythmias } \\
\hline Paroxysmal atrial fibrillation, $n(\%)$ & $50(26.7)$ \\
\hline Chronic atrial fibrillation, $n(\%)$ & $29(15.5)$ \\
\hline Ventricular arrhythmias, $n(\%)$ & $93(49.7)$ \\
\hline Implantable device, $n(\%)$ & $172(92.0)$ \\
\hline Heart rate $($ mean $\pm \mathrm{SD})$, beats/min & $81.4 \pm 15.5$ \\
\hline Systolic blood pressure (mean $\pm \mathrm{SD}$ ), $\mathrm{mm} \mathrm{Hg}$ & $102.6 \pm 14.6$ \\
\hline Diastolic blood pressure (mean $\pm \mathrm{SD}$ ), $\mathrm{mm} \mathrm{Hg}$ & $67.9 \pm 9.8$ \\
\hline \multicolumn{2}{|l|}{ Medications } \\
\hline ACEI/ARB, $n(\%)$ & $141(75.4)$ \\
\hline$\beta$ blocker, $n(\%)$ & $157(84.0)$ \\
\hline Aldosterone antagonist, $n(\%)$ & $102(54.5)$ \\
\hline Furosemide, $n(\%)$ & $99(52.9)$ \\
\hline Bumetanide, $n(\%)$ & $11(5.8)$ \\
\hline Torsemide, $n(\%)$ & $64(34.2)$ \\
\hline Thiazide, $n(\%)$ & $25(13.4)$ \\
\hline Digoxin, $n(\%)$ & $102(54.6)$ \\
\hline Antiarrhythmics, $n(\%)$ & $80(42.8)$ \\
\hline Warfarin, $n(\%)$ & $121(64.7)$ \\
\hline Inotropes, $n(\%)$ & $75(40.1)$ \\
\hline \multicolumn{2}{|l|}{ Laboratory } \\
\hline Hematocrit (mean $\pm \mathrm{SD}), \%$ & $38.2 \pm 5.3$ \\
\hline Sodium $($ mean $\pm \mathrm{SD}), \mathrm{mEq} / \mathrm{L}$ & $135.9 \pm 4.3$ \\
\hline Potassium (mean $\pm \mathrm{SD}), \mathrm{mEq} / \mathrm{L}$ & $4.0 \pm 0.5$ \\
\hline Glucose $($ mean $\pm \mathrm{SD}), \mathrm{mg} / \mathrm{dL}$ & $115.1 \pm 35.7$ \\
\hline Blood urea nitrogen $($ mean $\pm \mathrm{SD}), \mathrm{mg} / \mathrm{dL}$ & $26.9 \pm 14.3$ \\
\hline Creatinine, $\mathrm{mg} / \mathrm{dL}$ & $1.4(1.1-1.6)$ \\
\hline
\end{tabular}

Table 1. Continued

\begin{tabular}{lc}
\hline \hline \multicolumn{1}{c}{ Characteristic } & \multicolumn{1}{c}{ Values } \\
\hline Total cholesterol (mean $\pm \mathrm{SD}), \mathrm{mg} / \mathrm{dL}$ & $136.2 \pm 47.6$ \\
Triglycerides (mean $\pm \mathrm{SD}), \mathrm{mg} / \mathrm{dL}$ & $114.9 \pm 79.7$ \\
& \\
\hline$N=187$. & \\
BMI $=$ body mass index & \\
NYHA $=$ New York Heart Association \\
PTCA $=$ percutaneous transluminal coronary angioplasty \\
ACEI $=$ angiotensin-converting enzyme inhibitor \\
ARB $=$ angiotensin-receptor blocker \\
\hline
\end{tabular}

Table 2. Baseline Subject Central Hemodynamics

\begin{tabular}{lc}
\hline \hline \multicolumn{1}{c}{ Characteristic } & Values \\
\hline Pulmonary artery systolic pressure, $\mathrm{mm} \mathrm{Hg}$ & $50.0 \pm 15.2$ \\
Pulmonary artery diastolic pressure, $\mathrm{mm} \mathrm{Hg}$ & $24.4 \pm 8.9$ \\
Pulmonary artery mean pressure, $\mathrm{mm} \mathrm{Hg}$ & $34.2 \pm 10.6$ \\
Right ventricular systolic pressure, $\mathrm{mm} \mathrm{Hg}$ & $49.4 \pm 14.6$ \\
Right ventricular diastolic pressure, $\mathrm{mm} \mathrm{Hg}$ & $11.4 \pm 7.0$ \\
Pulmonary-capillary wedge pressure, $\mathrm{mm} \mathrm{Hg}$ & $23.3 \pm 8.3$ \\
Systemic vascular resistance, $\mathrm{dyn} / \mathrm{s} / \mathrm{cm}^{5}$ & $1,694.8 \pm 596.3$ \\
Pulmonary vascular resistance, $\mathrm{dyn} / \mathrm{s} / \mathrm{cm}^{5}$ & $266.8 \pm 180.0$ \\
Cardiac output, $\mathrm{L} / \mathrm{min}$ & $3.8 \pm 1.2$ \\
Cardiac index, $\mathrm{L} / \mathrm{min} / \mathrm{m}^{2}$ & $1.9 \pm 0.5$ \\
Central venous $\mathrm{pressure}, \mathrm{mm} \mathrm{Hg}$ & $11.3 \pm 6.5$
\end{tabular}

subjects, $P<.001$; FVC of $3.4 \pm 1.0 \mathrm{~L}$ in white subjects vs $2.7 \pm 0.7 \mathrm{~L}$ in non-white subjects, $P<.001)$ and lower $\mathrm{FEV}_{1} / \mathrm{FVC}(0.73 \pm 0.09$ vs $0.77 \pm 0.13$, respectively, $P=.02$ ). A normal spirometric ventilatory pattern was observed in $47(25.1 \%)$ subjects, an obstructive pattern was observed in $8(4.3 \%)$ subjects, a restrictive pattern was observed in $95(50.8 \%)$ subjects, and a mixed pattern was observed in $37(19.8 \%)$ subjects. The average maximum oxygen consumption on cardiopulmonary exercise testing was $11.9 \pm 2.7 \mathrm{~mL} / \mathrm{kg} / \mathrm{min}$.

\section{Effect of Clinical Variables and Medications on Spirometric Parameters}

No difference was observed in spirometric variables between subjects with different clinical characteristics, smoking, lung disease, and diabetes mellitus (data not shown). Also, there was no difference in spirometric variables in subjects receiving angiotensin-converting enzymes or angiotensin II receptor blockers, aldosterone, or $\beta$ blockers. However, there was a difference in subjects receiving inotropic agents. Specifically, in subjects receiving inotropes versus those not receiving inotropes, percent-of-predicted FVC was $68.8 \pm 16.3$ versus $74.2 \pm 16.0(P=.03)$, percent-of-predicted $\mathrm{FEV}_{1}$ was $64.6 \pm 15.2$ versus $69.1 \pm 16.7(P=.064), \mathrm{FEV}_{1}$ was $2.3 \pm 0.7 \mathrm{~L}$ versus 


\section{Spirometry in SubJects Listed for Heart Transplantation}

Table 3. Association Between Spirometric Parameters and Outcomes in Subjects Listed for Heart Transplantation

\begin{tabular}{|c|c|c|c|}
\hline Spirometric Parameter & Hazard Ratio & $95 \% \mathrm{CI}$ & $P$ \\
\hline \multicolumn{4}{|c|}{$\begin{array}{l}\text { Primary end point (death or ventricular } \\
\text { assist device implantation) }\end{array}$} \\
\hline $\mathrm{FEV}_{1}, \mathrm{~L}$ & 0.93 & $0.61-1.41$ & .72 \\
\hline $\mathrm{FEV}_{1}, \%$ predicted & 1.00 & $0.98-1.02$ & .80 \\
\hline FVC, L & 0.90 & $0.65-1.25$ & .52 \\
\hline FVC, $\%$ predicted & 0.99 & $0.98-1.01$ & .53 \\
\hline $\mathrm{FEV}_{1} / \mathrm{FVC}$ & 1.01 & $0.98-1.03$ & .65 \\
\hline \multicolumn{4}{|c|}{$\begin{array}{l}\text { Secondary end point (death, ventricular } \\
\text { assist device implantation, or } \\
\text { urgent transplantation) }\end{array}$} \\
\hline $\mathrm{FEV}_{1}, \mathrm{~L}$ & 0.94 & $0.72-1.21$ & .62 \\
\hline $\mathrm{FEV}_{1}, \%$ predicted & 1.00 & $0.99-1.01$ & .75 \\
\hline FVC, L & 0.92 & $0.76-1.13$ & .43 \\
\hline FVC, \% predicted & 1.00 & $0.99-1.01$ & .58 \\
\hline $\mathrm{FEV}_{1} / \mathrm{FVC}$ & 1.01 & $0.99-1.02$ & .45 \\
\hline
\end{tabular}

$2.4 \pm 0.7 \mathrm{~L}(P=.18), \mathrm{FVC}$ was $3.1 \pm 0.9 \mathrm{~L}$ versus $3.3 \pm 1.0 \mathrm{~L}(P=.16)$, and $\mathrm{FEV}_{1} / \mathrm{FVC}$ was $0.74 \pm 0.13$ versus $0.75 \pm 0.08(P=.80)$. There was no association between diuretic dose and spirometric variables or maximum oxygen consumption (data not shown).

\section{Outcomes}

The median follow-up until death, left ventricular assist device implantation, or heart transplantation was 5.5 months (interquartile range of 2.3-15.2); the total follow-up was 223 person-years. There were 19 deaths, 28 left ventricular assist device implantations, and 74 urgent transplantations for a total of 47 primary end point events $(25.1 \%)$ and 121 secondary end point events $(64.7 \%)$. The annual event rate was $21.0 \%$ (95\% CI $15.8-28.0$ ) for the primary end point and $54.1 \%$ (95\% CI 45.3-64.6) for the secondary end point.

\section{Association of Spirometry With Outcomes}

There was no association between spirometric parameters and outcomes in our population in both primary and secondary analyses (Table 3). The hazard ratios of FEV 1 and percent-of-predicted $\mathrm{FEV}_{1}$ were 0.93 (95\% CI $0.61-$ $1.41, P=.72)$ and 1.00 (95\% CI $0.98-1.02, P=.80$ ), respectively, in primary analysis and 0.94 (95\% CI $0.72-$ $1.21, P=.62)$ and 1.00 (95\% CI 0.99-1.01, $P=.75$ ), respectively, in secondary analysis. Similarly, the hazard ratios of FVC and percent-of-predicted FVC were 0.90 (95\% CI 0.65-1.25, $P=.52$ ) and 0.99 (95\% CI $0.98-$ $1.01, P=.53)$, respectively, in primary analysis and 0.92 (95\% CI 0.76-1.13, $P=.43$ ) and 1.00 (95\% CI $0.99-$ $1.01, P=.58)$, respectively, in secondary analysis. The fractional polynomial and restricted cubic spline models did not reveal nonlinear associations between spirometric parameters and outcomes.

\section{Association of Spirometry With Central Hemodynamics}

There were significant correlations between central hemodynamics and spirometric variables. Elevated pulmonary artery and right ventricular systolic pressures were significantly associated with lower absolute and percent-

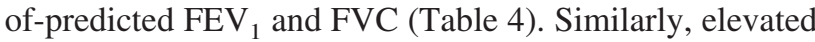
pulmonary-capillary wedge and central venous pressures were negatively correlated with absolute and percent-ofpredicted $\mathrm{FEV}_{1}$ and $\mathrm{FVC}$, whereas cardiac output was positively correlated with absolute and percent-of-predicted $\mathrm{FEV}_{1}$ and FVC. $\mathrm{FEV}_{1} / \mathrm{FVC}$ was not correlated with hemodynamics.

\section{Association of Ventilatory Patterns With Outcomes}

Using a normal ventilatory pattern as the reference, an obstructive, restrictive, or mixed ventilatory pattern did not confer increased risk for the primary or secondary end points. Specifically, for the primary end point, the hazard ratios of obstructive, restrictive, and mixed patterns were 0.57 (95\% CI 0.12-2.64, $P=.47$ ), 1.10 (95\% CI 0.55$2.18, P=.80$ ), and 1.09 (95\% CI 0.46-2.60, $P=.84$ ), respectively, with normal respiratory pattern as the reference (Fig. 1A). For the secondary end point, the hazard ratios of obstructive, restrictive, and mixed patterns were 0.68 (95\% CI 0.24-1.98, $P=.48$ ), 1.48 (95\% CI $0.94-$ 2.33, $P=.94$ ), and 1.54 (95\% CI 0.89-2.67, $P=.89$ ), respectively (Fig. 1B).

\section{Spirometry and Post-Transplant Survival}

Perioperative $30-\mathrm{d}$ mortality was $1.4 \%$, and $1-\mathrm{y}$ posttransplant survival was $97.1 \%$. Baseline spirometry was not associated with post-transplant survival (Fig. 2). At $1 \mathrm{y}$, survival was $100 \%, 96.0 \%, 100 \%$, and $96.5 \%$ for subjects with baseline obstructive, restrictive, mixed, and normal spirometric patterns, respectively (log-rank chisquare $=2.80, P=.42$ ).

\section{Outcomes in Subjects Without Spirometric Data}

The median follow-up of the 158 subjects without available spirometric data was 7.2 months (interquartile range of 2.4-26.4); total follow-up was 248 person-years. Among these subjects, there were $47(26.6 \%)$ primary outcome events and $101(63.9 \%)$ secondary outcome events. The annual event rates were $17 \%$ (95\% CI 12.5-23.0) for the primary outcome and $40.8 \%$ (95\% CI 33.6-49.6) for the secondary outcome. There was no difference in out- 


\section{Spirometry in SubJects Listed for Heart Transplantation}

Table 4. Association Between Spirometric Parameters and Central Hemodynamics

\begin{tabular}{|c|c|c|c|c|c|}
\hline Parameter & $\begin{array}{l}\text { Pulmonary Artery } \\
\text { Systolic Pressure }\end{array}$ & $\begin{array}{l}\text { Right Ventricular } \\
\text { Systolic Pressure }\end{array}$ & $\begin{array}{l}\text { Pulmonary-Capillary } \\
\text { Wedge Pressure }\end{array}$ & $\begin{array}{l}\text { Central Venous } \\
\text { Pressure }\end{array}$ & Cardiac Output \\
\hline \multicolumn{6}{|l|}{$\mathrm{FEV}_{1}$} \\
\hline Coefficient (r) & -0.15 & -0.24 & -0.15 & -0.24 & 0.22 \\
\hline$P$ & .04 & .009 & .05 & .005 & .004 \\
\hline \multicolumn{6}{|l|}{ Predicted $\mathrm{FEV}_{1}$} \\
\hline Coefficient (r) & -0.16 & -0.20 & -0.21 & -0.27 & 0.10 \\
\hline$P$ & .03 & .03 & .006 & .002 & .20 \\
\hline \multicolumn{6}{|l|}{ FVC } \\
\hline Coefficient (r) & -0.15 & -0.26 & -0.14 & -0.18 & 0.23 \\
\hline$P$ & .04 & .005 & .07 & .04 & .003 \\
\hline \multicolumn{6}{|l|}{ Predicted FVC } \\
\hline Coefficient (r) & -0.16 & -0.24 & -0.23 & -0.22 & 0.08 \\
\hline$P$ & .03 & .01 & .003 & .01 & .29 \\
\hline \multicolumn{6}{|l|}{$\mathrm{FEV}_{1} / \mathrm{FVC}$} \\
\hline Coefficient (r) & 0.03 & 0.07 & 0.00 & -0.13 & -0.04 \\
\hline$P$ & .67 & .46 & .99 & .13 & .59 \\
\hline
\end{tabular}
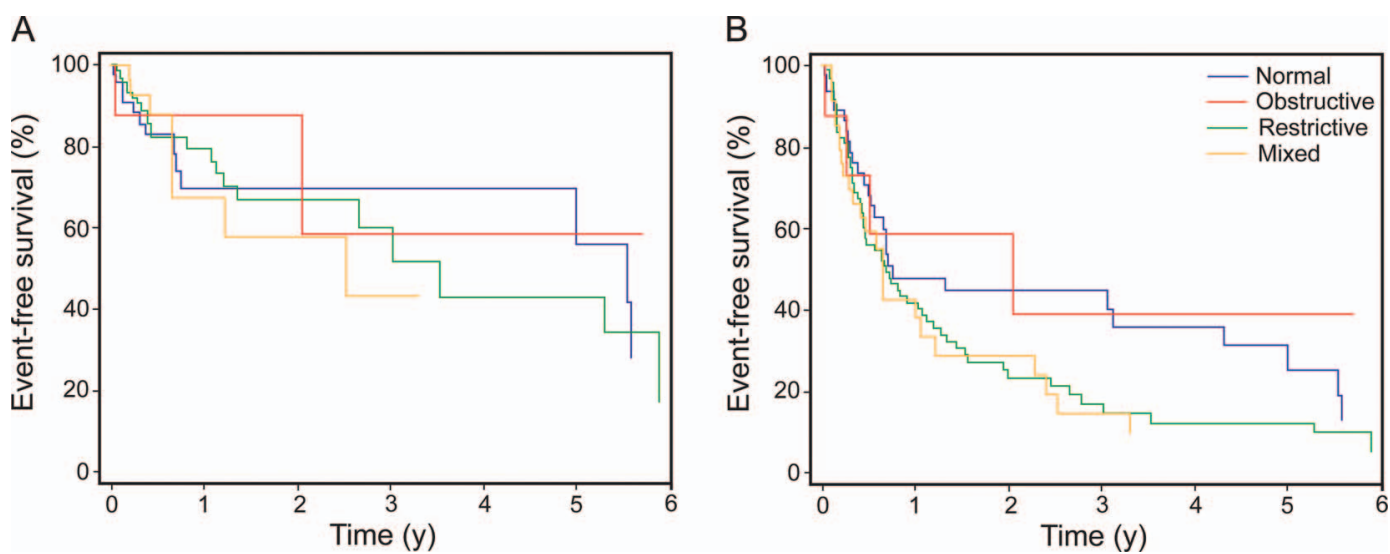

Fig. 1. Survival of subjects listed for heart transplantation with different spirometric ventilatory patterns. A: Kaplan-Meier estimates for the primary outcome (death and left ventricular assist device implantation). B: Kaplan-Meier estimates for the secondary outcome (death, urgent transplantation, and left ventricular assist device implantation).

comes between those subjects with and without spirometric data $(P=.54$ and $P=.15$, respectively) (Fig. 3).

\section{Discussion}

The main observation of our study is that spirometric variables were not associated with outcomes in subjects with advanced heart failure listed for heart transplant. Similarly, we did not observe any prognostic association of obstructive, restrictive, or mixed ventilatory pattern with outcomes. To our knowledge, this is the first study reporting the association between spirometric parameters and outcomes in this population. Studies investigating the prognostic value of spirometry in subjects with acute ${ }^{25}$ or stable $^{24,26}$ heart failure showed that spirometric variables predict outcomes in these stage $\mathrm{C}$ heart failure populations.

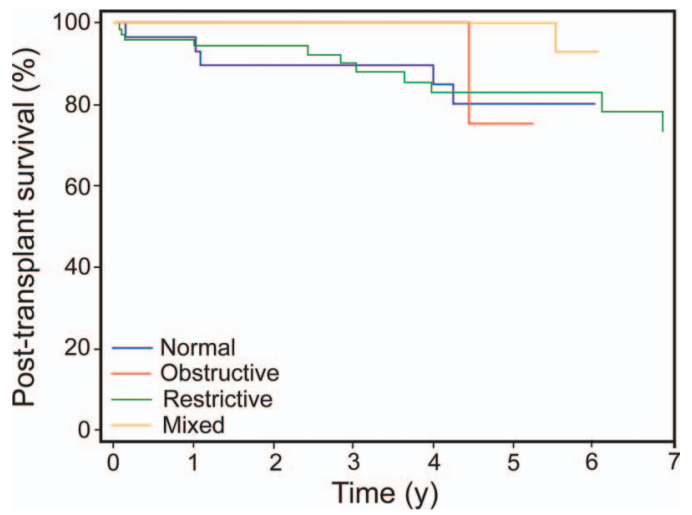

Fig. 2. Post-transplant survival according to baseline spirometric pattern. 
A

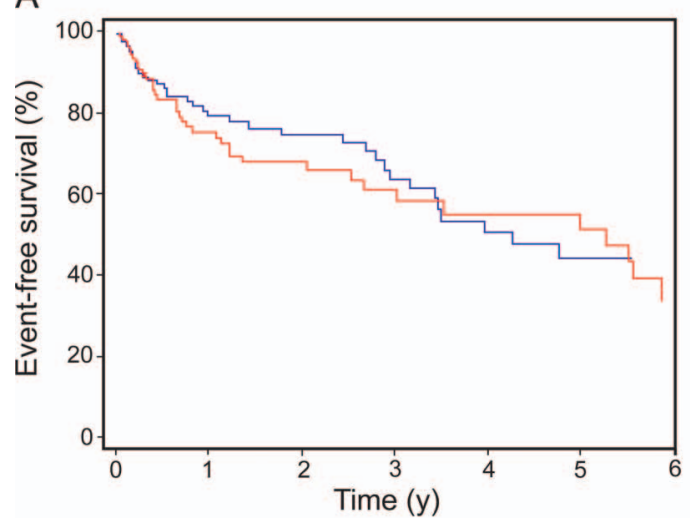

B

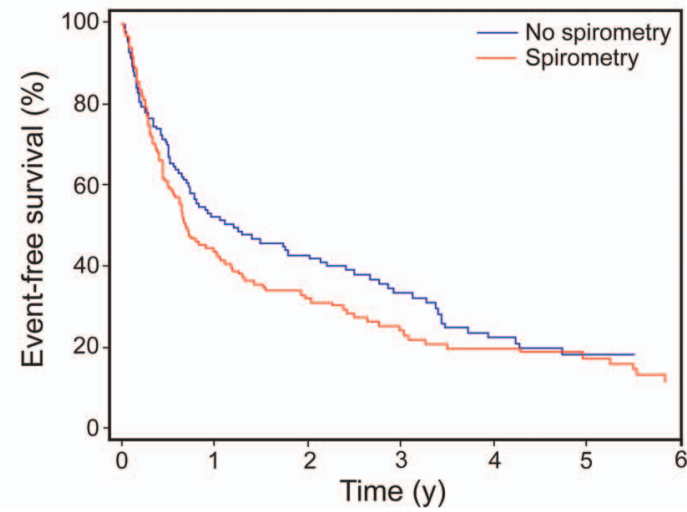

Fig. 3. Survival of subjects listed for heart transplantation with and without spirometry. A: Kaplan-Meier estimates for the primary outcome (death and left ventricular assist device implantation). B: Kaplan-Meier estimates for the secondary outcome (death, urgent transplantation, and left ventricular assist device implantation).

However, we did not observe a similar association in our study, in which we included subjects with stage D heart failure exclusively.

There are several potential explanations for our findings. The population of patients with heart failure listed for heart transplantation is selected to be free of severe endorgan dysfunction, which may considerably attenuate the prognostic value of spirometry. Impaired cardiac function is the initiating process for heart failure, and as the disease progresses, the patients enter a state of systemic illness that impacts multiple organ systems and finally leads to advanced disease. These heart failure-induced changes include also changes in the pulmonary system. The pulmonary and cardiac systems are intimately linked anatomically and physiologically; because of this, changes in the cardiac system have profound effects on the pulmonary system, also causing abnormalities in spirometric parameters. However, these spirometric abnormalities might be just indicators of the heart-lung relationship in this specific population of heart failure patients without underlying prognostic importance. It has been reported that spirometry is not useful for diagnosis and grading of pulmonary diseases in subjects with heart failure undergoing heart transplantation because of this heart-lung relationship. ${ }^{31}$ This may be the case for prognostic purposes as well.

Previous studies showed that subjects with heart failure often develop significant abnormalities in pulmonary function $^{12,14,15,32}$ that range from relatively marginal dysfunction to more significant spirometric abnormalities, both restrictive and obstructive. ${ }^{14,33}$ In our population, pulmonary function was impaired in $75 \%$ of subjects, whereas only a small proportion had a history of chronic lung disease, confirming the association of heart failure with reduced pulmonary function and the findings of previous studies that a high proportion of subjects with heart failure have spirometric ventilatory abnormalities. ${ }^{14} \mathrm{~A}$ higher pro- portion of subjects had a restrictive pattern than an obstructive or mixed pattern, which has been described in other studies as well. In fact, this imbalance of case mix of spirometric ventilatory patterns in our cohort, in conjunction with the small number of events among subjects with obstructive and mixed patterns, may be the reason for the observed lack of association of spirometric patterns with outcomes rather than the absence of biologic association. The specific mechanism or mechanisms leading to changes or no change in lung function in patients with heart failure are not completely clear. Possible mechanisms that have been suggested include chronic pulmonary congestion and hypertension, ${ }^{34}$ respiratory muscle weakness, ${ }^{35}$ low cardiac output, ${ }^{36}$ and cardiomegaly. ${ }^{15,32}$

Data on the importance of reduced spirometric values, especially $\mathrm{FEV}_{1}$, have been conflicting also. In a retrospective study of 186 out-patients with heart failure and reduced ejection fraction (mainly stage $\mathrm{C}$ and New York Heart Association classes I and II), only severe air-flow obstruction $\left(\mathrm{FEV}_{1}<50 \%\right.$ of predicted value) appeared to be a predictor of reduced survival. ${ }^{37}$ In another prospective study of 439 subjects with heart failure and reduced ejection fraction, $\mathrm{FEV}_{1}<80 \%$ of predicted was associated with reduced survival. ${ }^{26}$ This underscores that more studies are needed to definitely answer the question of the importance of pulmonary function abnormalities in heart failure survival.

In our study, we observed no association between spirometric values and functional capacity of subjects listed for heart transplantation. This observation is in accordance with the findings of another study in which the influence of spirometric variables on peak exercise capacity diminished as symptoms of heart failure worsened, and there was no relation in the New York Heart Association class III-IV subjects. ${ }^{38} \mathrm{We}$ also observed a significant association of spirometric variables and central hemodynamics, in 


\section{Spirometry in Subjects Listed for Heart Transplantation}

accordance with previous studies. ${ }^{39,40}$ Increased pressures in the pulmonary circulation have been associated with bronchial obstruction, leading to pulmonary function abnormalities. ${ }^{41}$ With medical therapy, there is significant improvement in restrictive or obstructive abnormalities, and this improvement is explained by a reduction of pulmonary pressures, with a subsequent decrease in interstitial edema and bronchial wall congestion. ${ }^{14,39,42}$

Our study has some important limitations. There were no available spirometric data on all listed subjects. However, there was no difference in the outcomes (primary and secondary) between the subjects with and without spirometric data, so the limitation of selection bias could be considered as relatively weak. We did not obtain diffusion capacity data in our subjects during their evaluation; thus, we cannot describe any difference in the prognostic value of this test in this specific heart failure population. We used fixed cutoff points for percent-of-predicted $\mathrm{FEV}_{1}$ and FVC to describe obstructive versus restrictive spirometric patterns instead of using, for example, the lower limit of normal. Finally, the case mix of the various spirometric patterns is unbalanced, and considering the small number of subjects with obstructive and mixed patterns (and the corresponding small number of events), the observed lack of association may merely reflect lack of power rather than absence of biologic association. A comparative study would be needed to evaluate whether different criteria for the various spirometric patterns would be more valuable in this group of subjects.

\section{Conclusions}

In summary, spirometric parameters were not associated with outcomes in the homogeneous group of subjects with heart failure listed for heart transplantation. Because severe heart failure leads to significant reduction in $\mathrm{FEV}_{1}$ and FVC, the majority of advanced patients with heart failure will have impaired spirometric values. Therefore, the usefulness of spirometry to diagnose and grade pulmonary function abnormalities (obstruction or restriction) in this population needs further evaluation.

\section{REFERENCES}

1. Curtis LH, Whellan DJ, Hammill BG, Hernandez AF, Anstrom KJ, Shea AM, Schulman KA. Incidence and prevalence of heart failure in elderly persons, 1994-2003. Arch Intern Med 2008;168(4):418424.

2. Roger VL, Go AS, Lloyd-Jones DM, Benjamin EJ, Berry JD, Borden WB, et al. Heart disease and stroke statistics-2012 update: a report from the American Heart Association. Circulation 2012;125(1):e2e220.

3. Writing Group Members, Lloyd-Jones D, Adams RJ, Brown TM, Carnethon M, Dai S, et al. Heart disease and stroke statistics-2010 update: a report from the American Heart Association. Circulation 2010;121(7):e46-e215.

4. Goldberg RJ, Ciampa J, Lessard D, Meyer TE, Spencer FA. Longterm survival after heart failure: a contemporary population-based perspective. Arch Intern Med 2007;167(5):490-496.

5. Teng TH, Finn J, Hobbs M, Hung J. Heart failure: incidence, case fatality, and hospitalization rates in Western Australia between 1990 and 2005. Circ Heart Fail 2010;3(2):236-243.

6. Yeung DF, Boom NK, Guo H, Lee DS, Schultz SE, Tu JV. Trends in the incidence and outcomes of heart failure in Ontario, Canada: 1997 to 2007. CMAJ 2012;184(14):E765-E773.

7. Heidenreich PA, Albert NM, Allen LA, Bluemke DA, Butler J, Fonarow GC, et al. Forecasting the impact of heart failure in the United States: a policy statement from the American Heart Association. Circ Heart Fail 2013;6(3):606-619.

8. Mancini D, Lietz K. Selection of cardiac transplantation candidates in 2010. Circulation 2010;122(2):173-183.

9. Strueber M, O'Driscoll G, Jansz P, Khaghani A, Levy WC, Wieselthaler GM, HeartWare Investigators. Multicenter evaluation of an intrapericardial left ventricular assist system. J Am Coll Cardiol 2011;57(12):1375-1382.

10. Aurora P, Edwards LB, Christie J, Dobbels F, Kirk R, Kucheryavaya AY, et al. Registry of the International Society for Heart and Lung Transplantation: eleventh official pediatric lung and heart/lung transplantation report-2008. J Heart Lung Transplant 2008;27(9):978983.

11. Health Resources and Services Administration: Organ Procurement and Transplantation Network. United States Department of Health and Human Services. http://optn.transplant.hrsa.gov/. Accessed November 25,2014

12. Dimopoulou I, Daganou M, Tsintzas OK, Tzelepis GE. Effects of severity of long-standing congestive heart failure on pulmonary function. Respiratory medicine 1998;92(12):1321-1325.

13. Kindman LA, Vagelos RH, Willson K, Prikazky L, Fowler M. Abnormalities of pulmonary function in patients with congestive heart failure, and reversal with ipratropium bromide. Am J Cardiol 1994; 73(4):258-262.

14. Wright RS, Levine MS, Bellamy PE, Simmons MS, Batra P, Stevenson LW, et al. Ventilatory and diffusion abnormalities in potential heart transplant recipients. Chest 1990;98(4):816-820.

15. Olson TP, Beck KC, Johnson BD. Pulmonary function changes associated with cardiomegaly in chronic heart failure. J Card Fail 2007;13(2):100-107.

16. Barr RG, Bluemke DA, Ahmed FS, Carr JJ, Enright PL, Hoffman EA, et al. Percent emphysema, airflow obstruction, and impaired left ventricular filling. N Engl J Med 2010;362(3):217-227.

17. Lizak MK, Zakliczyński M, Jarosz A, Zembala M, Kalarus Z. Restrictive pattern in spirometry as a predictor of poor survival in chronic heart failure patients on betaceptor-antagonist, with possible indications for heart transplantation. Ann Transplant 2011;16(4):1624.

18. Engström G, Lind P, Hedblad B, Wollmer P, Stavenow L, Janzon L, Lindgärde F. Lung function and cardiovascular risk: relationship with inflammation-sensitive plasma proteins. Circulation 2002; 106(20):2555-2560.

19. Schünemann HJ, Dorn J, Grant BJ, Winkelstein W Jr, Trevisan M. Pulmonary function is a long-term predictor of mortality in the general population: 29-year follow-up of the Buffalo Health Study. Chest 2000;118(3):656-664.

20. Hole DJ, Watt GC, Davey-Smith G, Hart CL, Gillis CR, Hawthorne VM. Impaired lung function and mortality risk in men and women: findings from the Renfrew and Paisley prospective population study. BMJ 1996;313(7059):711-715; discussion 715-716. 


\section{Spirometry in Subjects Listed for Heart Transplantation}

21. Georgiopoulou VV, Kalogeropoulos AP, Psaty BM, Rodondi N, Bauer DC, Butler AB, et al. Lung function and risk for heart failure among older adults: the Health ABC Study. Am J Med 2011;124(4): 334-341.

22. Gottdiener JS, Arnold AM, Aurigemma GP, Polak JF, Tracy RP, Kitzman DW, et al. Predictors of congestive heart failure in the elderly: the Cardiovascular Health Study. J Am Coll Cardiol 2000; 35(6): 1628-1637.

23. Kannel WB, D'Agostino RB, Silbershatz H, Belanger AJ, Wilson PW, Levy D. Profile for estimating risk of heart failure. Arch Intern Med 1999;159(11):1197-1204.

24. Olson TP, Denzer DL, Sinnett WL, Wilson T, Johnson BD. Prognostic value of resting pulmonary function in heart failure. Clin Med Insights Circ Respir Pulm Med 2013;7:35-43.

25. Iversen KK, Kjaergaard J, Akkan D, Kober L, Torp-Pedersen C, Hassager C, et al. The prognostic importance of lung function in patients admitted with heart failure. Eur J Heart Fail 2010;12(7): 685-691.

26. Miniati M, Monti S, Bottai M, Passino C, Emdin M, Poletti R. Forced expiratory volume in one second: prognostic value in systolic heart failure. Int J Cardiol 2013;168(2):1573-1574

27. Klein OL, Kalhan R, Williams MV, Tipping M, Lee J, Peng J, Smith LJ. Lung spirometry parameters and diffusion capacity are decreased in patients with type 2 diabetes. Diabet Med 2012;29(2):212-219.

28. American Thoracic Society. Standardization of spirometry, 1994 update. Am J Respir Crit Care Med 1995;152(3):1107-1136.

29. American Thoracic Society. Lung function testing: selection of reference values and interpretative strategies. Am Rev Respir Dis 1991; 144(5):1202-1218.

30. Binder H, Sauerbrei W, Royston P. Comparison between splines and fractional polynomials for multivariable model building with continuous covariates: a simulation study with continuous response. Stat Med 2013;32(13):2262-2277.

31. Lizak MK, Zakliczyński M, Jarosz A, Zembala M. The influence of chronic heart failure on pulmonary function tests in patients undergoing orthotopic heart transplantation. Transplant Proc 2009;41(8): 3194-3197.
32. Olson TP, Beck KC, Johnson JB, Johnson BD. Competition for intrathoracic space reduces lung capacity in patients with chronic heart failure: a radiographic study. Chest 2006;130(1):164-171.

33. Hosenpud JD, Stibolt TA, Atwal K, Shelley D. Abnormal pulmonary function specifically related to congestive heart failure: comparison of patients before and after cardiac transplantation. Am J Med 1990; 88(5):493-496.

34. Ayres SM. Mechanisms and consequences of pulmonary edema: cardiac lung, shock lung, and principles of ventilatory therapy in adult respiratory distress syndrome. Am Heart J 1982;103(1):97112

35. Daganou M, Dimopoulou I, Alivizatos PA, Tzelepis GE. Pulmonary function and respiratory muscle strength in chronic heart failure: comparison between ischaemic and idiopathic dilated cardiomyopathy. Heart 1999;81(6):618-620.

36. Mancini DM, Henson D, LaManca J, Levine S. Respiratory muscle function and dyspnea in patients with chronic congestive heart failure. Circulation 1992;86(3):909-918.

37. Mascarenhas J, Lourenço P, Lopes R, Azevedo A, Bettencourt P. Chronic obstructive pulmonary disease in heart failure. Prevalence, therapeutic and prognostic implications. Am Heart J 2008;155(3): 521-525.

38. Ingle L, Shelton RJ, Cleland JG, Clark AL. Poor relationship between exercise capacity and spirometric measurements in patients with more symptomatic heart failure. J Card Fail 2005;11(8):619623.

39. Ries AL, Gregoratos G, Friedman PJ, Clausen JL. Pulmonary function tests in the detection of left heart failure: correlation with pulmonary artery wedge pressure. Respiration 1986;49(4):241-250.

40. Cundrle I Jr, Johnson BD, Somers VK, Scott CG, Rea RF, Olson LJ. Effect of cardiac resynchronization therapy on pulmonary function in patients with heart failure. Am J Cardiol 2013;112(6):838-842.

41. Meyer FJ, Ewert R, Hoeper MM, Olschewski H, Behr J, Winkler J, et al. Peripheral airway obstruction in primary pulmonary hypertension. Thorax 2002;57(6):473-476.

42. Faggiano P, Lombardi C, Sorgato A, Ghizzoni G, Spedini C, Rusconi C. Pulmonary function tests in patients with congestive heart failure: effects of medical therapy. Cardiology 1993;83(1-2):30-35. 